\title{
Inhibition of Rat Muscle and Liver Phosphofructokinases by High Doses of Ethanol
}

\author{
Sergey Vladimirovich Lelevich, ${ }^{1}$ Vladislav Victorovich Khrustalev, ${ }^{2}$ \\ and Eugene Victorovich Barkovsky ${ }^{2}$ \\ ${ }^{1}$ Department of Clinical Laboratory Diagnostics, Allergology and Immunology, Grodno State Medical University, \\ Gorkogo 80, 230009 Grodno, Belarus \\ ${ }^{2}$ Department of General Chemistry, Belarusian State Medical University, Dzerzinskogo 83, 220116 Minsk, Belarus
}

Correspondence should be addressed to Vladislav Victorovich Khrustalev; vvkhrustalev@mail.ru

Received 29 July 2013; Revised 18 September 2013; Accepted 23 September 2013

Academic Editor: Paul W. Doetsch

Copyright (C) 2013 Sergey Vladimirovich Lelevich et al. This is an open access article distributed under the Creative Commons Attribution License, which permits unrestricted use, distribution, and reproduction in any medium, provided the original work is properly cited.

\begin{abstract}
Activities of both rat muscle and liver phosphofructokinases are significantly inhibited after a single ethanol intake in the dose of $2.5 \mathrm{~g}$ per $\mathrm{kg}$ of body weight. This inhibitory effect is indirect, since ethanol in concentration $(50 \mathrm{mM})$ close to that established after $2.5 \mathrm{~g}$ per $\mathrm{kg}$ of body weight intake cannot decrease their activities in vitro. Inhibition of liver phosphofructokinase activity after the $5.0 \mathrm{~g}$ per $\mathrm{kg}$ ethanol intake may be direct, since liver phosphofructokinase activity decreases in vitro when ethanol is added to supernatants of rat liver tissue in $100 \mathrm{mM}$ concentration. According to the results of molecular docking, ethanol at high concentrations can be bound by adenine-binding pocket of the allosteric ADP-binding site of liver phosphofructokinase (Asp543, Phe308, Phe538, and Phe671) and its activation by ADP can be blocked by $\mathrm{C}_{2} \mathrm{H}_{5} \mathrm{OH}$ molecule. Direct inhibition of muscle phosphofructokinase activity, probably due to the binding of ethanol to the similar ADP-binding site, is possible when the concentration of ethanol $(500 \mathrm{mM})$ is much higher than the level which can be established in living cells. So, inhibition of muscle phosphofructokinase activity after a single $5.0 \mathrm{~g}$ per $\mathrm{kg}$ intake is indirect and probably linked with the inhibition of the enzyme by elevated citrate and phosphoenolpyruvate levels.
\end{abstract}

\section{Introduction}

Phosphofructokinase catalyzes phosphorylation of fructose6-phosphate to fructose-1,6-bisphosphate. This reaction is a key regulatory step in the glycolysis [1]. Phosphofructokinase activity is regulated through allosteric inhibition and activation. High ATP to ADP ratio inhibits phosphofructokinase and glycolysis as well [1]. Indeed, ADP (the product of the reaction) is an allosteric activator of the activity of that enzyme [2]. Phosphofructokinase is also activated by AMP and fructose-2,6-bisphosphate and inhibited by phosphoenolpyruvate and citrate [3].

Mammalian phosphofructokinase is a tetramer. There are three genes encoding monomers of phosphofructokinase. They are designated as muscle, liver, and platelet phosphofructokinases. The muscle enzyme is a homotetramer (composed of four identical muscle subunits) [1]. Liver also expresses predominantly homotetramer composed of four liver subunits [1].

Ethanol can be found in 163 entries in the Protein Data Bank (http://www.pdb.org/). It can interact with many proteins being a part of the solvent. Alcohol dehydrogenases bind (and metabolize) ethanol specifically [1]. Ethanol also binds $\alpha 7$-nAChRs (nicotinic acetylcholine receptors) as an agonist [4], GABA receptors (gamma-aminobutyric acid receptors) as a positive allosteric modulator [5], NMDA receptor (N-methyl-D-aspartate receptor) as an antagonist [6], and glycine receptor as an agonist [7]. Moreover, ethanol activates $\mathrm{G}$ protein-gated inwardly rectifying $\mathrm{K}^{+}$channels (GIRK) [8]. A putative alcohol-binding pocket located in the cytoplasmic domains of GIRK channels has been suggested [8]. That alcohol-binding pocket is thought to be similar to the specific alcohol-binding pocket described for the odorant binding protein LUSH from Drosophila melanogaster [8-10]. 
In our recent work we showed that such glycolytic enzyme as pyruvate kinase (both muscle and liver isoenzymes) can also be directly inhibited by very high $(500 \mathrm{mM})$ doses of ethanol [11]. Taking into account the ability of ethanol to form hydrogen bonds and participate in polar, cation-pi, and hydrophobic interactions with proteins, it is very important to check whether its effect on activity of a certain enzyme is direct or indirect. Direct effect is a consequence of ethanol physical binding by a certain binding pocket of a protein [8]. Indirect effect is not caused by the physical binding of ethanol by a protein of interest. Instead of that, ethanol may act through changing the fluidity of the lipid bilayer [8], through the neural or hormonal regulation, through the binding with other proteins, or even DNA [12], and so forth.

The main purpose of this study was to find out whether ethanol can directly inhibit activities of muscle and liver phosphofructokinases. The answer to this question was positive: high concentrations of ethanol decrease phosphofructokinase activity in vitro. The second question to solve was whether direct inhibition of phosphofructokinase by ethanol may have any connections with the effects of acute alcohol intoxication on the activity of that enzyme? According to our results, inhibition of muscle phosphofructokinase activity after the acute alcohol intoxication is not a consequence of its direct inhibition by ethanol. Muscle enzyme can be directly inhibited only by $500 \mathrm{mM}$ ethanol. Direct inhibition of liver phosphofructokinase takes place when the concentration of ethanol reaches $100 \mathrm{mM}$, so it is possible that after the intake of $5.0 \mathrm{~g}$ per $\mathrm{kg}$ of ethanol its activity can be inhibited directly.

Differences in structures of allosteric ADP-binding sites for muscle and liver phosphofructokinases have been discussed. Because of those differences ethanol can directly inhibit liver phosphofructokinase activity at lower concentrations than in the case with its muscle homologue.

\section{Materials and Methods}

Acute alcohol intoxication has been modeled in twenty two rats (males, 180-220 g), seven rats have been used as a control group. All the rats have been fasted for 11 hours before the ethanol (or equivolume $0.9 \% \mathrm{NaCl}$ ) admission via stomach intubation. Seven rats received $25 \%$ ethanol in water solution in the dosage of $1.0 \mathrm{~g}$ per $\mathrm{kg}$ of body weight; seven rats received $25 \%$ ethanol in dosage of $2.5 \mathrm{~g}$ per $\mathrm{kg}$ of body weight; and eight rats received $25 \%$ ethanol in dosage of $5.0 \mathrm{~g}$ per $\mathrm{kg}$ of body weight. Rats were decapitated after 1 hour from the ethanol or saline intake. The doses of ethanol used in this study $(1.0,2.5$, and $5.0 \mathrm{~g}$ per $\mathrm{kg}$ of body weight) are standard for experiments on acute ethanol intoxication consequences [13-15].

The dosage of ethanol equal to $5.0 \mathrm{~g}$ per $\mathrm{kg}$ of body weight is widely used in studies on the effects of heavy acute alcohol intoxication. According to the different sources that dosage of ethanol delivered via stomach intubation results in $80.43 \mathrm{mM}$ $[14,16]$ or $108.0 \pm 2.3 \mathrm{mM}[17]$ peak blood levels.

The dosage of ethanol equal to $2.5 \mathrm{~g}$ per $\mathrm{kg}$ of body weight is used for models of acute average dose alcohol intoxication. Peak blood levels after a single $2.5 \mathrm{~g}$ per kg ethanol intake vary from $23.9 \pm 11.3 \mathrm{mM}$ [18], $39.3 \pm 10.0 \mathrm{mM}$ [19], $40.43 \mathrm{mM}$ [14] up to $55.0 \pm 7.1 \mathrm{mM}[20]$.

The dosage of ethanol equal to $1.0 \mathrm{~g}$ per $\mathrm{kg}$ of body weight corresponds to the low dose acute alcohol intoxication. Peak blood alcohol levels after that dose of ethanol vary significantly: $7.2 \pm 0.43 \mathrm{mM}[13], 11.8 \pm 1.4 \mathrm{mM}$ [21], $15.9 \pm 2.2 \mathrm{mM}$ [22], and $18.3 \pm 1.0 \mathrm{mM}[23]$.

In vitro experiment on the direct ethanol effect on phosphofructokinases activities has been performed on supernatants of liver and muscle tissues of six rats (males, 180$220 \mathrm{~g}$ ). We performed experiments with four final concentrations of ethanol $(5,50,100$, and $500 \mathrm{mM})$. The lowest concentration of ethanol used in in vitro experiment $(5 \mathrm{mM})$ corresponds to the lowest dosage of ethanol $(1.0 \mathrm{~g}$ per $\mathrm{kg}$ of body weight) in in vivo experiment [13]. The concentration of $50 \mathrm{mM}$ can be established after the intake of $2.5 \mathrm{~g}$ per $\mathrm{kg}$ of ethanol [20]. The concentration of $100 \mathrm{mM}$ corresponds to $5.0 \mathrm{~g}$ per $\mathrm{kg}$ ethanol administration [17]. The highest concentration of ethanol $(500 \mathrm{mM})$ was also used to study the direct effect of ethanol on enzymatic activity, even though that concentration cannot be established in vivo.

Liver and muscle tissues have been homogenized in glass homogenizers. Supernatants have been obtained after the centrifugation of homogenates.

Enzymatic activity of phosphofructokinase in supernatants of liver and muscle tissues has been measured by a method suggested by Undervud and Newsholme [24] (in the fructose-bisphosphate aldolase, alpha-glycerophosphate dehydrogenase, and triosephosphate dehydrogenase coupled assay). Incubation mixture contained $70 \mathrm{mM}$ tris- $\mathrm{HCl}$ buffer $\mathrm{pH}=8.2$; $2 \mathrm{mM}$ AMP; $1 \mathrm{mM}$ EDTA; $0.2 \mathrm{mM}$ NADH; $1 \mathrm{mM}$ 2-merkaptoethanol; $0.3 \mathrm{mM} \mathrm{KCN;} 5 \mathrm{mM} \mathrm{MgCl}_{2}$; 50 microgram of fructose-bisphosphate aldolase; 10 microgram of the alpha-glycerophosphate dehydrogenase, and 10 microgram of triosephosphate dehydrogenase. All the probes were incubated for 10 minutes at $25^{\circ} \mathrm{C}$. Then, fructose-6phosphate (final concentration is equal to $1 \mathrm{mM}$ ) and ATP (final concentration is equal to $1 \mathrm{mM}$ ) were added to the test probes. Fructose-6-phosphate was not added to the control probes. Absorption of control probes was measured at $340 \mathrm{~nm}$ on "SOLAR" spectrophotometer. Then, test probes were further incubated for 20 minutes at $20^{\circ} \mathrm{C}$. Activities have been calculated from the differences in absorbance of test and control probes at $340 \mathrm{~nm}$. Activities are expressed in nmol of substrate per $\mathrm{mg}$ of tissue per minute ( $\mathrm{nmol} / \mathrm{mg} / \mathrm{min}$ ).

There are two X-ray structures of phosphofructokinase $(3 \mathrm{O} 8 \mathrm{~N}$ and $3 \mathrm{O} 8 \mathrm{~L})$ submitted to the Protein Data Bank (http://www.pdb.org/). Both of those PDB files describe rabbit muscle phosphofructokinase [2]. In $3 \mathrm{O} 8 \mathrm{~N}$ file, there are three molecules of ADP bound to three different sites of a single phosphofructokinase [2]. We used 308L file as a template to construct 3D models of human and rat muscle and liver homologous enzymes because in that file there are two ATP molecules and a single ADP molecule bound to the protein [2]. One of the three binding sites was thought to be specific for ADP and not ATP binding [2].

Swiss Model server [25] (http://swissmodel.expasy.org/) has been used for the modeling of rat and human enzymes 
based on their amino acid sequences from GenBank (NP_001160158; AAH94212.1; NP_002617.3; NP_037322.1).

The Docking Server [26, 27] (http://www.dockingserver .com/) has been used for molecular docking of ethanol, ADP, and ATP to 3D models of phosphofructokinases, as well as for docking of ethanol to the LUSH protein of Drosophila melanogaster (1OOF). That server automatically used an area for docking which includes a specific site for ADP binding in case of phosphofructokinases and ethanol-binding pocket in case of LUSH. There were 10 runs for each docking. We calculated average levels of free energies of binding for those 10 runs. Then, we calculated binding constants according to the formula given below

$$
K=e^{-\Delta G / R T}
$$

In that formula, $K$ is a binding constant, $\Delta G$ is a free energy of binding (in $\mathrm{kcal} / \mathrm{mol}$ ), $R$ is a gas constant (1.99. $\left.10^{-3} \mathrm{kcal} / \mathrm{mol} \cdot \mathrm{K}\right)$, and $T$ is a temperature $(310 \mathrm{~K})$.

We used all the available sequences of phosphofructokinases from the Ensembl data base [28]. If there are different directions of symmetric mutational pressure in sequences from the same alignment, evolutionary distances between them usually become higher [29]. To avoid that problem, we excluded those sequences in which GC-content in third codon positions (3GC) is lower than 50\% [11]. Moreover, we excluded partial sequences (except those from Lamprey genome) and sequences with regions which cannot be aligned properly. Finally, we excluded sequences from different species of fish because there are several copies of tissuespecific phosphofructokinases in their genomes.

Lancelet (Branchiostoma floridae) homologue of phosphofructokinases (XM_002607302) from vertebrates has been found with the help of BLAST search (http://blast.ncbi .nlm.nih.gov/Blast.cgi).

Sequences have been aligned by MUSCLE algorithm included into MEGA 5 program [30]. We calculated JTT amino acid evolutionary distances between sequences [31]. The dendrogram has been built by UPGMA method [31].

Activities of both muscle and liver phosphofructokinases were inhibited by average and high bolus doses of ethanol (see Table 1). Activity of muscle phosphofructokinase has been decreased 1.23 times after the admission of $2.5 \mathrm{~g}$ of ethanol per $1 \mathrm{~kg}$ of body weight and 1.48 times after the admission of $5.0 \mathrm{~g}$ per $\mathrm{kg}$. Activity of liver phosphofructokinase has been decreased about 1.43 times after the admission of both average and high doses of ethanol (see Table 1).

It was shown that alcohol consumption (both acute and chronic) leads to the decrease of ATP level and increase of ADP level in cells $[32,33]$. So, the ATP/ADP ratio becomes lower during the period of ethanol intake. Elevated levels of ADP should have a stimulatory effect on the activity of phosphofructokinase [2]. However, our data showed that activities of muscle and liver phosphofructokinases can be somehow decreased by ethanol. This decrease of enzymatic activities is possible in case when the compensatory mechanism linked with ADP level increase is not working yet (during acute alcohol intoxication).
One of the possible pathways of phosphofructokinase activity inhibition during acute alcohol intoxication may be linked with elevated $\mathrm{NADH} / \mathrm{NAD}^{+}$ratio. Ethanol consumption leads to the NADH accumulation (alcohol dehydrogenases and aldehyde dehydrogenases produce NADH from $\mathrm{NAD}^{+}$) $[1,34]$. Isocitrate dehydrogenase is inhibited by elevated HADH level, allowing an increase in citrate level [1]. Citrate is a known inhibitor of phosphofructokinase activity $[3,34]$.

\section{Results and Discussion}

As we have shown previously, acute alcohol intoxication (5 $\mathrm{g}$ per $\mathrm{kg}$ of body weight) causes decrease of muscle and liver pyruvate kinases activities (they become 1.47 and 1.35 times lower, resp.) [11]. Because of this reason, phosphoenolpyruvate level should increase during acute alcohol intoxication. Phosphoenolpyruvate is a known inhibitor of phosphofructokinase activity [3]. The most interesting fact about phosphofructokinase activity inhibition by citrate and phosphoenolpyruvate is that those substances require sufficient level of ATP for their action [3]. In other words, both citrate and phosphoenolpyruvate can inhibit phosphofructokinase activity when the level of ATP is relatively high [3]. Those conditions may be established during acute alcohol intoxication.

The nature of the inhibitory effect of ethanol on muscle and liver phosphofructokinases activities observed in in vivo experiments has been clarified in the in vitro experiment (see Table 2). Activity of muscle phosphofructokinase was inhibited by the $500 \mathrm{mM}$ ethanol only. Such a high concentration of ethanol is impossible inside living cells. It means that even though ethanol can directly interact with muscle phosphofructokinase and inhibit its activity, that kind of direct inhibition is possible only in vitro.

Activity of liver phosphofructokinase has been significantly inhibited by $100 \mathrm{mM}$ ethanol (see Table 2). That concentration of ethanol is very high, and it may be established in living cells after the enormous alcohol intake $(100 \mathrm{mM}$ is equal to $4.6 \%$ o). It is known that blood alcohol levels higher than $5 \%$ are lethal. However, there are some known cases when blood alcohol levels were around 8-10\%o [35]. So, direct inhibition of liver phosphofructokinase activity is possible in humans after the intake of very high doses of alcohol.

Peak blood alcohol level in rats after the single intake of $5.0 \mathrm{~g}$ per $\mathrm{kg}$ of ethanol may reach $108.0 \pm 2.3 \mathrm{mM}$ [17]. So, inhibitory effect of acute alcohol intake can be direct. It means that inhibition of liver phosphofructokinase activity after the intake of high dose of alcohol may happen because of both direct and indirect mechanisms (probably, due to inhibition by citrate and phosphoenolpyruvate in the presence of sufficient ATP concentration).

ADP is an allosteric activator of phosphofructokinase (PFK) [2]. The site for ADP binding includes Asp173, Met174, Asp179, Tyr214, Phe308, Asn341, Ser377, Asn381, Phe538, Asp543, and Phe671 residues [2]. According to the results of molecular docking of ADP to models of rat and human muscle and liver phosphofructokinases, all these eleven 
TABLE 1: Activities (nmol/mg/min) of muscle and liver phosphofructokinases after the acute alcohol intoxication.

\begin{tabular}{lcccc}
\hline Enzymes & Control group $(n=7)$ & \multicolumn{2}{c}{ Ethanol dosage } \\
& & $1.0 \mathrm{~g} / \mathrm{kg}(n=7)$ & $2.5 \mathrm{~g} / \mathrm{kg}(n=7)$ & $5.0 \mathrm{~g} / \mathrm{kg}(n=8)$ \\
\hline Muscle PFK & $97.9 \pm 13.2$ & $94.7 \pm 7.0$ & $79.5 \pm 9.4^{*}$ & $66.3 \pm 7.1^{*}$ \\
Liver PFK & $8.4 \pm 0.7$ & $8.6 \pm 0.8$ & $5.9 \pm 0.5^{*}$ & $5.8 \pm 0.5^{*}$ \\
\hline
\end{tabular}

Significant $(P<0.05)$ differences with control group are shown by asterisks $\left(^{*}\right)$.

TABLE 2: Activities (nmol/mg/min) of phosphofructokinases in muscle and liver supernatants after the addition of ethanol.

\begin{tabular}{lccccc}
\hline \multirow{2}{*}{ Enzymes } & \multirow{2}{*}{ Control $(n=6)$} & $5 \mathrm{mM}(n=6)$ & $50 \mathrm{mM}(n=6)$ & $100 \mathrm{mM}(n=6)$ & $500 \mathrm{mM}(n=6)$ \\
\hline Muscle PFK & $90.3 \pm 7.9$ & $75.2 \pm 14.7$ & $85.9 \pm 7.2$ & $82.4 \pm 10.2$ & $67.3 \pm 6.6^{*}$ \\
Liver PFK & $8.6 \pm 0.6$ & $8.2 \pm 0.2$ & $8.1 \pm 0.7$ & $5.3 \pm 0.7^{*}$ & $5.0 \pm 0.6^{*}$ \\
\hline
\end{tabular}

Significant $(P<0.05)$ differences with control group are shown by asterisks $\left({ }^{*}\right)$.

amino acid residues are predicted as those binding ADP. Phenylalanine residues (Phe308, Phe538, and Phe671) can participate in either cation-pi or hydrophobic interactions with adenine. Asp543 is able to make a hydrogen bond with $-\mathrm{NH}_{2}$ group of adenine.

As one can see in Figure 1, ethanol may be bound by the same part of ADP binding site which is able to bind adenine, at least, in the model of rat muscle phosphofructokinase. Three phenylalanine residues (Phe308, Phe538, and Phe671) are able to participate in either hydrophobic or cation-pi interactions with ethanol, while Asp543 usually takes part in polar interactions.

In the same manner, ethanol can be docked to the adenine binding pocket of ADP binding site from the model of rat liver phosphofructokinase (see Figure 2). Even though positions of ethanol in the allosteric site of both enzymes are similar, there are some differences. In the variant of ethanol docking to the rat muscle phosphofructokinase with lowest total free energy of binding, the main role is played by Phe538 (its decomposed free energy of binding is equal to $-0.4589 \mathrm{kcal} / \mathrm{mol})$ and Asp543 $(-0.4915 \mathrm{kcal} / \mathrm{mol})$. In the best docking of ethanol to the rat liver phosphofructokinase, the main role is played by Val545 $(-0.3043 \mathrm{kcal} / \mathrm{mol})$. Val545 participates in hydrophobic interactions with ethanol.

As one can see in Figure 3, Val545 from liver phosphofructokinase is aligned with Leu546 from muscle phosphofructokinase. Val545 seems to be more suitable for hydrophobic interactions with ethanol than Leu546. As to Ala542 from muscle phosphofructokinase, it has a positive free energy of binding with ethanol. The place of Ala542 is occupied by Ser541 in liver phosphofructokinase. So, some amino acid substitutions in the linear part of predicted ethanol binding site might influence its ability to bind that ligand (see Figure 3).

It is interesting to mention that the known ethanolbinding site of the LUSH protein (according to 1OOF [9], 3B7A, and 3B86 [10] 3D structures) also includes hydrophobic amino acids interacting with $-\mathrm{CH}_{2}-\mathrm{CH}_{3}$ tail of ethanol (Val58 and Phe113). However, hydrophilic part of the ethanol molecule (-OH group) makes hydrogen bonds with Ser52 and Thr57 residues of LUSH $[9,10]$, while in case of phosphofructokinases, that group participates in cation-pi and polar interactions.

Average free energies of binding for ATP, ADP, and ethanol are given in Table 3. It is important to highlight that free energies of binding for ADP are lower than those for ATP. As one can see in Table 4, the difference in binding constants for ADP and ATP is rather high. So, the site for ADP binding should be very specific [2].

Average free energies of binding for ethanol are about 3.3 times higher than those for ADP if we are talking about muscle phosphofructokinases. For liver phosphofructokinases, average free energies of binding for ADP are about 3.0 times lower than those for ethanol. Liver enzymes bind ethanol better than muscle enzymes, while those liver enzymes bind ADP worse than muscle enzymes (see Tables 3 and 4).

Of course, binding constants for ethanol are much lower than those constants for ADP. It means that ethanol may somehow bind allosteric site for ADP but only at rather high concentrations. Indeed, results of in vitro experiment support the data from Table 4: concentration of ethanol should be $100 \mathrm{mM}$ and higher for liver and $500 \mathrm{mM}$ and higher for muscle phosphofructokinase.

On the other hand, average free energy of ethanol binding for LUSH protein is $-2.03 \mathrm{kcal} / \mathrm{mol}$, which is just $8.5 \%$ lower than average free energy of binding for the model of human liver phosphofructokinase $(9.6 \%$ lower than that of the model of the rat enzyme). The constant of ethanol binding for LUSH protein (26.86) is just 1.29 times higher than that for the model of human liver phosphofructokinase (1.33 times higher than for the model of rat liver phosphofructokinase). Interestingly, according to the Docking Server results for LUSH protein and ethanol, decomposed free energy of hydrogen bond formation by Ser52 $(-0.1157 \mathrm{kcal} / \mathrm{mol})$ is lower than the decomposed free energies of hydrophobic interactions with Phel13 $(-0.4007 \mathrm{kcal} / \mathrm{mol})$ and Val58 $(-0.2221 \mathrm{kcal} / \mathrm{mol})$, while Thr57 is mentioned among amino acids participating in other interactions $(-0.0404 \mathrm{kcal} / \mathrm{mol})$. That data approves a high probability of ethanol binding by the nonspecific site of liver phosphofructokinase described in this study, since $\Delta G$ and $K$ for the specific binding site of LUSH are close to those for ADP-binding pocket of modeled enzymes. 


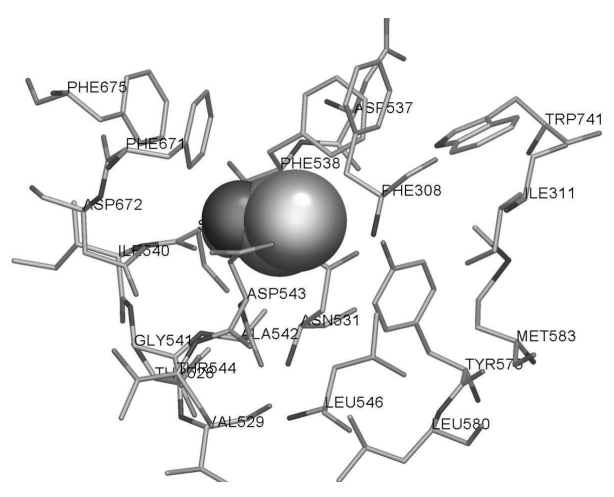

(a)

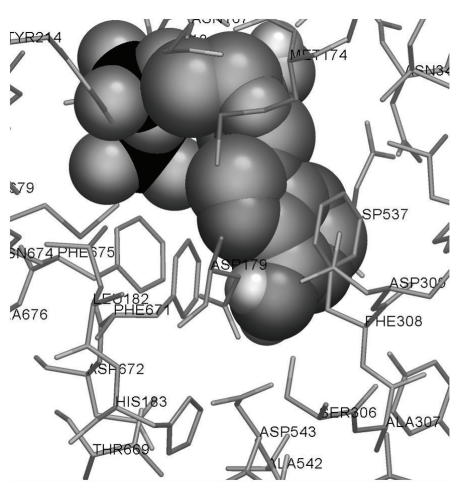

(b)

FIGURE 1: Results of the docking of ethanol (a) and ADP (b) to the model of rat muscle phosphofructokinase. Ligands are shown by spheres, interacting amino acid residues are shown by cylinders, and other amino acid residues of the protein are hidden.

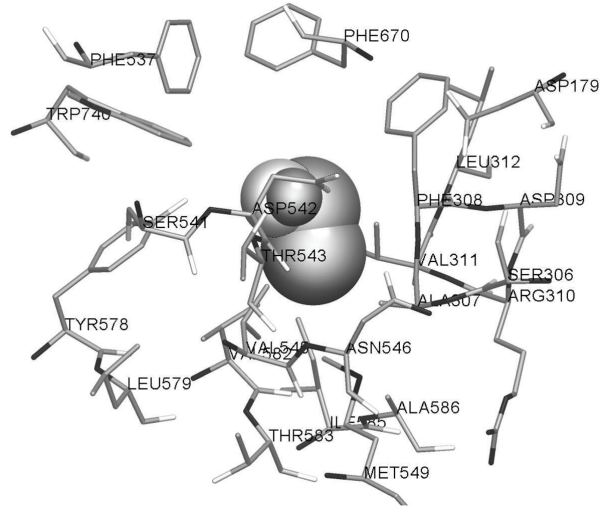

(a)

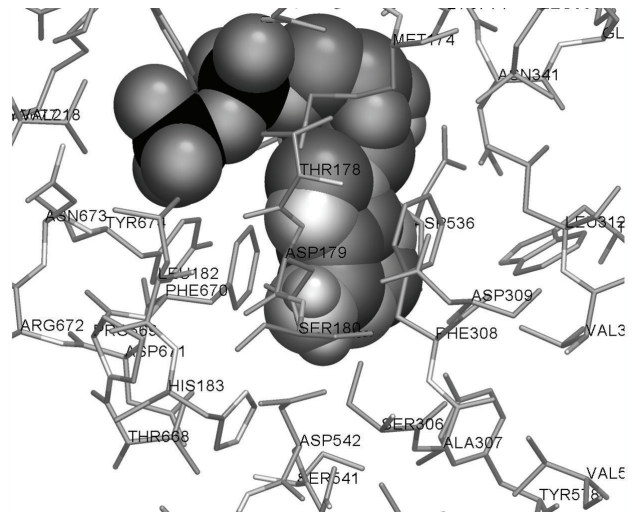

(b)

FIGURE 2: Results of the docking of ethanol (a) and ADP (b) to the model of rat liver phosphofructokinase. Ligands are shown by spheres, interacting amino acid residues are shown by cylinders, and other amino acid residues of the protein are hidden.

Homo sapiens, muscle 6-PFK

Rattus norvegicus, muscle 6-PFK

Homo sapiens, liver 6-PFK

Rattus norvegicus, liver 6-PFK

\section{$538 / 537 \quad 549 / 548$ \\ FSVGADTALNTI \\ FSIGADTALNTI \\ FSLGSDTAVNAA \\ FSLGSDTAVNAA}

FIGURE 3: Alignment of the linear part of the predicted ethanolbinding site for muscle (amino acids 538-549) and liver (amino acids 537-548) rat and human phosphofructokinases. Amino acid residues interacting with ethanol according to the results of molecular docking are shown by bold underlined type.

In our opinion, liver phosphofructokinases are directly inhibited by lower concentrations of ethanol than muscle phosphofructokinases because of certain amino acid substitutions fixed in the linear part of its binding site. Divergence of muscle and liver phosphofructokinases happened in the period between 713.2 and 535.7 Millions of years ago (Mya), just like the divergence between muscle and liver pyruvate kinases [11]. As one can see in Figure 4, a protein from lancelet proteome that is homologous to phosphofructokinases of vertebrates is an outgroup. The time of the divergence between lancelets and the predecessor of vertebrates is about 713.2 Mya [36]. There are tissue-specific (muscle and platelet) phosphofructokinases in the proteome of lamprey (see Figure 4). It means that divergence between three types of phosphofructokinases happened before the divergence of lampreys and other vertebrates (before 535.7 Mya [36]). According to the dendrogram from Figure 4, muscle and liver phosphofructokinases show more similarity with each other than each of them with their homologue expressed in platelets.

\section{Conclusions}

Activity of liver phosphofructokinase can be inhibited by high doses of ethanol (5 g per $\mathrm{kg}$ of body weight resulted in $100 \mathrm{mM}$ and higher peak blood levels) due to the binding of ethanol by the allosteric regulatory site.

Activity of muscle phosphofructokinase can also be inhibited due to the binding of ethanol at a similar site, while the concentration of that ligand necessary for enzyme inhibition $(500 \mathrm{mM})$ is higher than any possible ethanol concentration in living cells. 


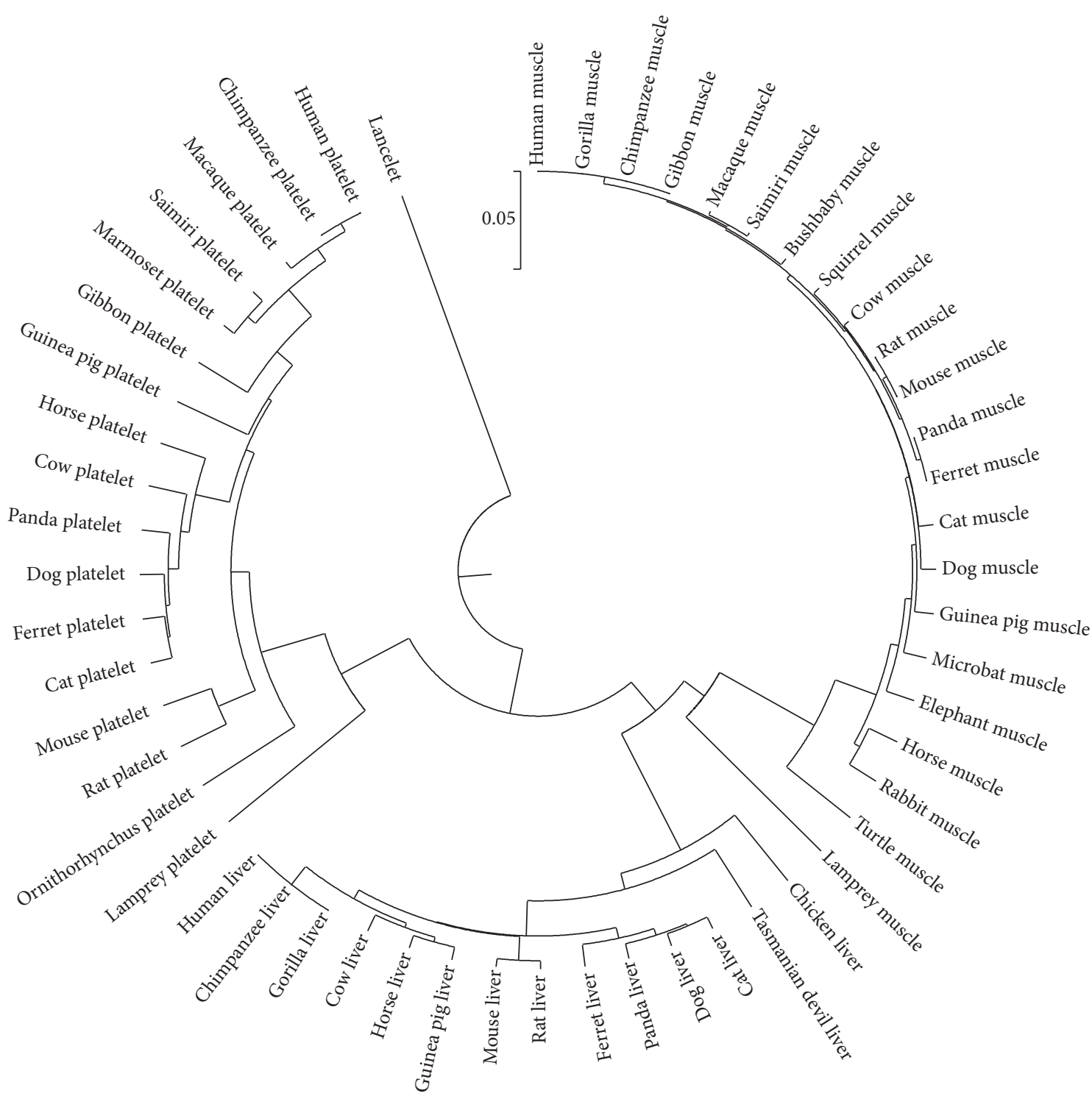

FIGURE 4: A circle dendrogram representing phylogenetic relations between muscle, liver, and platelet phosphofructokinases of vertebrates. Homologous protein of the lancelet is used as an outgroup. Phylogenetic tree is built by UPGMA method based on the JTT amino acid evolutionary distances.

TABLE 3: Average free energies of binding for ADP, ATP, and ethanol with human and rat muscle and liver phosphofructokinases.

\begin{tabular}{lcccr}
\hline Ligand & Rat muscle & Human muscle & Rat liver & Human liver \\
\hline ADP & $-6.011 \mathrm{kcal} / \mathrm{mol}$ & $-6.016 \mathrm{kcal} / \mathrm{mol}$ & $-5.724 \mathrm{kcal} / \mathrm{mol}$ & $-5.637 \mathrm{kcal} / \mathrm{mol}$ \\
ATP & $-5.375 \mathrm{kcal} / \mathrm{mol}$ & $-4.413 \mathrm{kcal} / \mathrm{mol}$ & $-5.255 \mathrm{kcal} / \mathrm{mol}$ & $-3.623 \mathrm{kcal} / \mathrm{mol}$ \\
Ethanol & $-1.812 \mathrm{kcal} / \mathrm{mol}$ & $-1.821 \mathrm{kcal} / \mathrm{mol}$ & $-1.852 \mathrm{kcal} / \mathrm{mol}$ & $-1.871 \mathrm{kcal} / \mathrm{mol}$ \\
\hline
\end{tabular}

TABLE 4: Binding constants for ADP, ATP, and ethanol with human and rat muscle and liver phosphofructokinases.

\begin{tabular}{lcccc}
\hline Ligand & & & & \\
& Rat muscle & Human muscle & Rat liver & Human liver \\
\hline ADP & 17049.58 & 17188.33 & 10706.98 & 9298.64 \\
ATP & 6080.97 & 1278.59 & 5006.03 & 355.28 \\
Ethanol & 18.86 & 19.14 & 20.13 & 20.76 \\
\hline
\end{tabular}


Inhibition of muscle and liver phosphofructokinases activities by a single intake of average dose of alcohol $(2.5 \mathrm{~g}$ per kg of body weight) is indirect and it is probably associated with increased $\mathrm{NADH} / \mathrm{NAD}^{+}$ratio.

\section{Conflict of Interests}

The authors declare that there is no conflict of interests regarding the publication of this paper.

\section{References}

[1] J. M. Berg, J. L. Tymoczko, and L. Stryer, Biochemistry, W. H. Freeman, New York, NY, USA, 5th edition, 2002.

[2] K. Banaszak, I. Mechin, G. Obmolova et al., "The crystal structures of eukaryotic phosphofructokinases from Baker's yeast and rabbit skeletal muscle," Journal of Molecular Biology, vol. 407, no. 2, pp. 284-297, 2011.

[3] G. Colombo, P. W. Tate, A. W. Girotti, and R. G. Kemp, "Interaction of inhibitors with muscle phosphofructokinase," The Journal of Biological Chemistry, vol. 250, no. 24, pp. 94049412, 1975.

[4] T. J. Davis and C. M. de Fiebre, "Alcohol's actions on neuronal nicotinic acetylcholine receptors," Biological Mechanisms, vol. 29, no. 3, pp. 179-185, 2006.

[5] P. Meera, R. W. Olsen, T. S. Otis, and M. Wallner, "Alcohol-and alcohol antagonist-sensitive human GABAA receptors: tracking $\delta$ subunit incorporation into functional receptors," Molecular Pharmacology, vol. 78, no. 5, pp. 918-924, 2010.

[6] H. Ren, A. K. Salous, J. M. Paul, K. A. Lamb, D. S. Dwyer, and R. W. Peoples, "Functional interactions of alcohol-sensitive sites in the N-methyl-D-aspartate receptor M3 and M4 domains," The Journal of Biological Chemistry, vol. 283, no. 13, pp. 8250-8257, 2008.

[7] G. E. Yevenes, G. Moraga-Cid, A. Avila et al., "Molecular requirements for ethanol differential allosteric modulation of glycine receptors based on selective $\mathrm{G} \beta \gamma$ modulation," The Journal of Biological Chemistry, vol. 285, no. 39, pp. 3020330213, 2010.

[8] P. Aryal, H. Dvir, S. Choe, and P. A. Slesinger, "A discrete alcohol pocket involved in GIRK channel activation," Nature Neuroscience, vol. 12, no. 8, pp. 988-995, 2009.

[9] S. W. Kruse, R. Zhao, D. P. Smith, and D. N. M. Jones, "Structure of a specific alcohol-binding site defined by the odorant binding protein LUSH from Drosophila melanogaster," Nature Structural Biology, vol. 10, no. 9, pp. 694-700, 2003.

[10] A. B. Thode, S. W. Kruse, J. C. Nix, and D. N. M. Jones, "The role of multiple hydrogen-bonding groups in specific alcohol binding sites in proteins: insights from structural studies of LUSH," Journal of Molecular Biology, vol. 376, no. 5, pp. 13601376, 2008.

[11] S. V. Lelevich, V. V. Khrustalev, E. V. Barkovsky, and T. A. Shedogubova, "The influence of ethanol on pyruvate kinases activity in vivo, in vitro, in silico," American Journal for Medical Biology Research, vol. 1, no. 1, pp. 6-15, 2013.

[12] S. Hassan, B. Duong, K.-S. Kim, and M. F. Miles, "Pharmacogenomic analysis of mechanisms mediating ethanol regulation of dopamine $\beta$-hydroxylase," The Journal of Biological Chemistry, vol. 278 , no. 40 , pp. 38860-38869, 2003.
[13] F. T. Crews, A. Mdzinarishvili, D. Kim, J. He, and K. Nixon, "Neurogenesis in adolescent brain is potently inhibited by ethanol," Neuroscience, vol. 137, no. 2, pp. 437-445, 2006.

[14] R. W. Saeed, S. Varma, T. Peng, K. J. Tracey, B. Sherry, and C. N. Metz, "Ethanol blocks leukocyte recruitment and endothelial cell activation in vivo and in vitro," Journal of Immunology, vol. 173, no. 10, pp. 6376-6383, 2004.

[15] E. A. Budygin, P. E. M. Phillips, D. L. Robinson, A. P. Kennedy, R. R. Gainetdinov, and R. M. Wightman, "Effect of acute ethanol on striatal dopamine neurotransmission in ambulatory rats," Journal of Pharmacology and Experimental Therapeutics, vol. 297, no. 1, pp. 27-34, 2001.

[16] Z. Zhong, G. E. Arteel, H. D. Connor et al., "Binge drinking disturbs hepatic microcirculation after transplantation: prevention with free radical scavengers," Journal of Pharmacology and Experimental Therapeutics, vol. 290, no. 2, pp. 611-620, 1999.

[17] M. Renis, V. Calabrese, A. Russo, A. Calderone, M. L. Barcellona, and V. Rizza, "Nuclear DNA strand breaks during ethanolinduced oxidative stress in rat brain," FEBS Letters, vol. 390, no. 2, pp. 153-156, 1996.

[18] F. Izbéki, T. Wittmann, S. Csáti, E. Jeszenszky, and J. Lonovics, "Opposite effects of acute and chronic administration of alcohol on gastric emptying and small bowel transit in rat," Alcohol and Alcoholism, vol. 36, no. 4, pp. 304-308, 2001.

[19] Y. Zhu, Y. Wang, B. Zhao et al., "Differential phosphorylation of GluN1-MAPKs in rat brain reward circuits following long-term alcohol exposure," PLoS ONE, vol. 8, Article ID e54930, 2013.

[20] V. V. Lelevich, The role of carbohydrates and energetic metabolism disturbances in brain cortex during pathogenesis of experimental alcoholism [Ph.D. thesis], 1991.

[21] A. A. Abdel-Rahman, "Reversal by ethanol of the hypotensive effect of clonidine in consicious spontaneously hypertensive rats," Hypertension, vol. 14, no. 5, pp. 531-541, 1989.

[22] A. Novier, Acute alcohol produces ataxia and cognitive impairments in aged animals: a comparison between young adults and aged rats [M.S. thesis], 2012.

[23] M. M. El-Mas, M. Fan, and A. A. Abdel-Rahman, "Endotoxemia-mediated induction of cardiac inducible nitric-oxide synthase expression accounts for the hypotensive effect of ethanol in female rats," Journal of Pharmacology and Experimental Therapeutics, vol. 324, no. 1, pp. 368-375, 2008.

[24] A. Undervud and E. Newsholme, "Properties of phosphofructokinase from rat liver and their relation to the control of glycolysis and gluconeogenesis," Biochemical Journal, vol. 95, no. 7, pp. 868-875, 1965.

[25] F. Kiefer, K. Arnold, M. Künzli, L. Bordoli, and T. Schwede, "The SWISS-MODEL Repository and associated resources," Nucleic Acids Research, vol. 37, no. 1, pp. D387-D392, 2009.

[26] R. Huey, G. M. Morris, A. J. Olson, and D. S. Goodsell, "Software news and update a semiempirical free energy force field with charge-based desolvation," Journal of Computational Chemistry, vol. 28, no. 6, pp. 1145-1152, 2007.

[27] Z. Bikadi and E. Hazai, "Application of the PM6 semi-empirical method to modeling proteins enhances docking accuracy of AutoDock," Journal of Cheminformatics, vol. 1, no. 1, article 15, 2009.

[28] P. Flicek, M. R. Amode, D. Barrell et al., "Ensembl 2012," Nucleic Acids Research, vol. 40, pp. D84-D90, 2012.

[29] V. V. Khrustalev and E. V. Barkovsky, "Unusual nucleotide content of Rubella virus genome as a consequence of biased RNA-editing: comparison with Alphaviruses," International 
Journal of Bioinformatics Research and Applications, vol. 7, no. 1, pp. 82-100, 2011.

[30] K. Tamura, D. Peterson, N. Peterson, G. Stecher, M. Nei, and S. Kumar, "MEGA5: molecular evolutionary genetics analysis using maximum likelihood, evolutionary distance, and maximum parsimony methods," Molecular Biology and Evolution, vol. 28, no. 10, pp. 2731-2739, 2011.

[31] M. Nei and S. Kumar, Molecular Evolution and Phylogenetics, Oxford University Press, New York, NY, USA, 2000.

[32] J. H. Helzberg, M. S. Brown, D. J. Smith, J. C. Gore, and E. R. Gordon, "Metabolic state of the rat liver with ethanol: comparison of in vivo 31phosphorus nuclear magnetic resonance spectroscopy with freeze clamp assessment," Hepatology, vol. 7, no. 1, pp. 83-88, 1987.

[33] I. V. Deaciuc, N. B. D'Souza, C. H. Lang, and J. J. Spitzer, "Effects of acute alcohol intoxication on gluconeogenesis and its hormonal responsiveness in isolated, perfused rat liver," Biochemical Pharmacology, vol. 44, no. 8, pp. 1617-1624, 1992.

[34] V. B. Abdiyev, "Effect of inhibitors and activators of phosphofructokinase on the oxygen uptake in plants under salinity conditions," Journal of Biology and Life Science, vol. 4, no. 2, 2013.

[35] P. Kintz, V. Cirimele, F. Mairot, M. Mithlmann, and B. Ludes, "Drug tests in 198 drivers implicated in non-fatal traffic accidents," Presse Medicale, vol. 29, no. 23, pp. 1275-1278, 2000.

[36] S. Kumar and S. B. Hedges, "Timetree2: species divergence times on the iPhone," Bioinformatics, vol. 27, no. 14, pp. 20232024, 2011. 

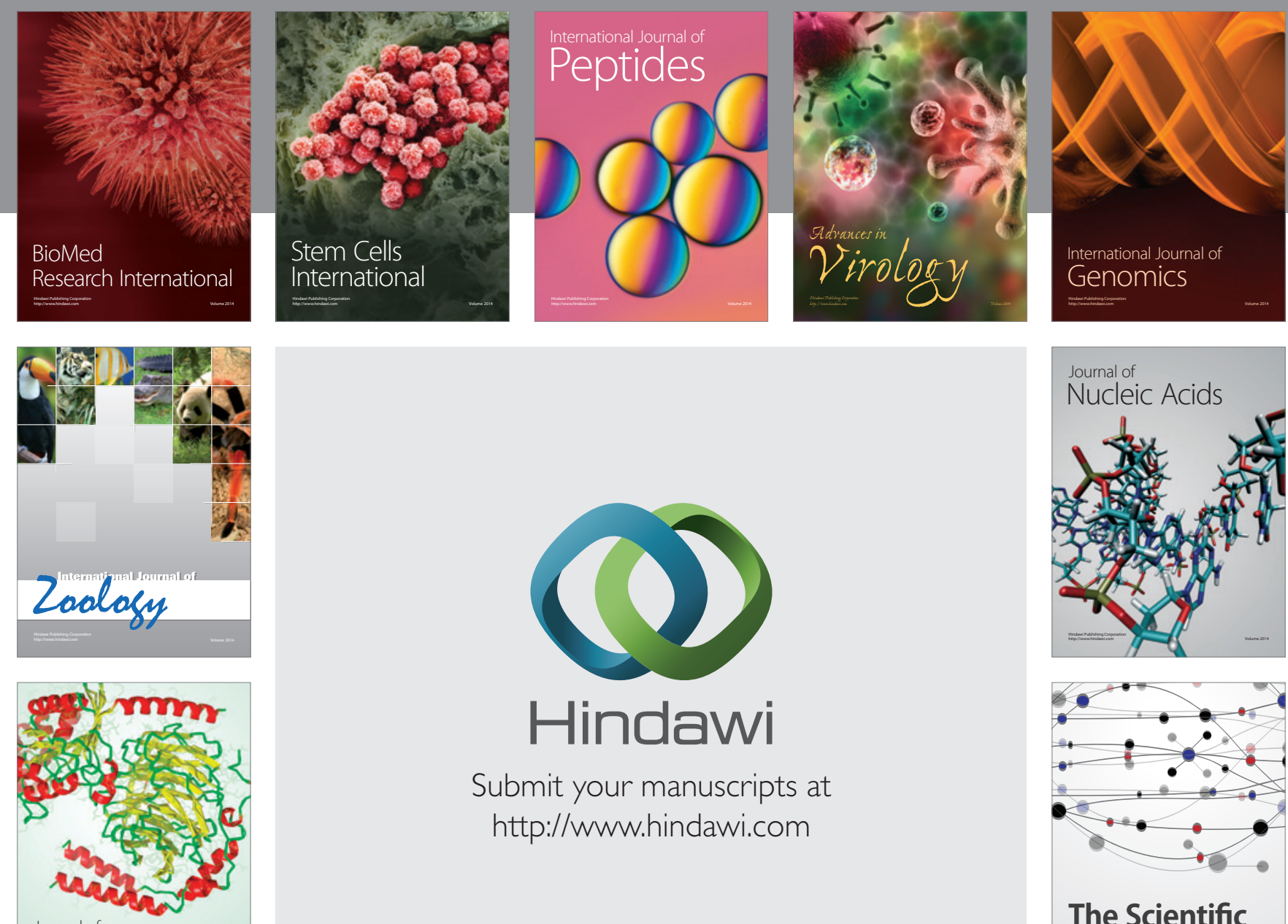

Submit your manuscripts at

http://www.hindawi.com

Journal of
Signal Transduction
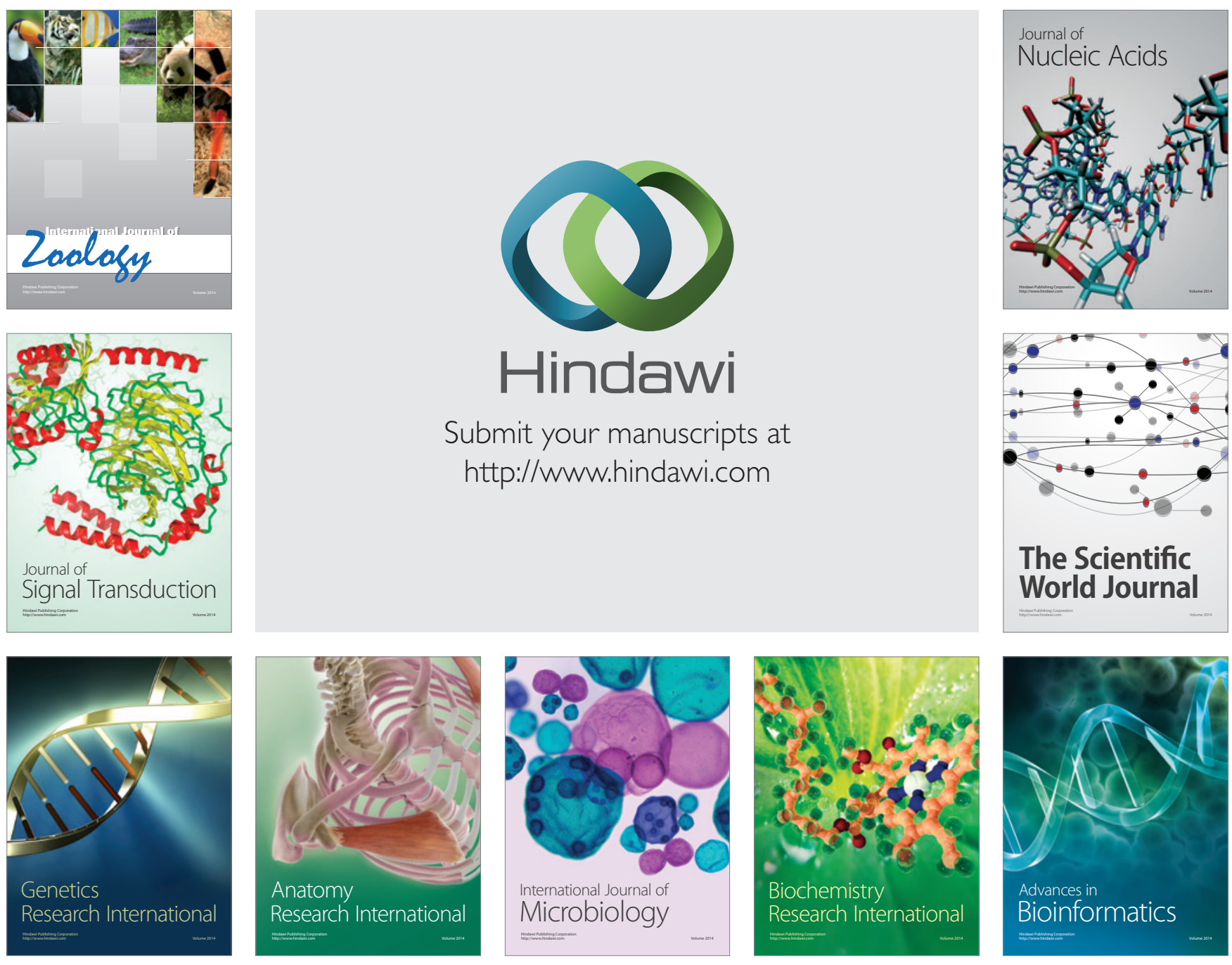

The Scientific World Journal
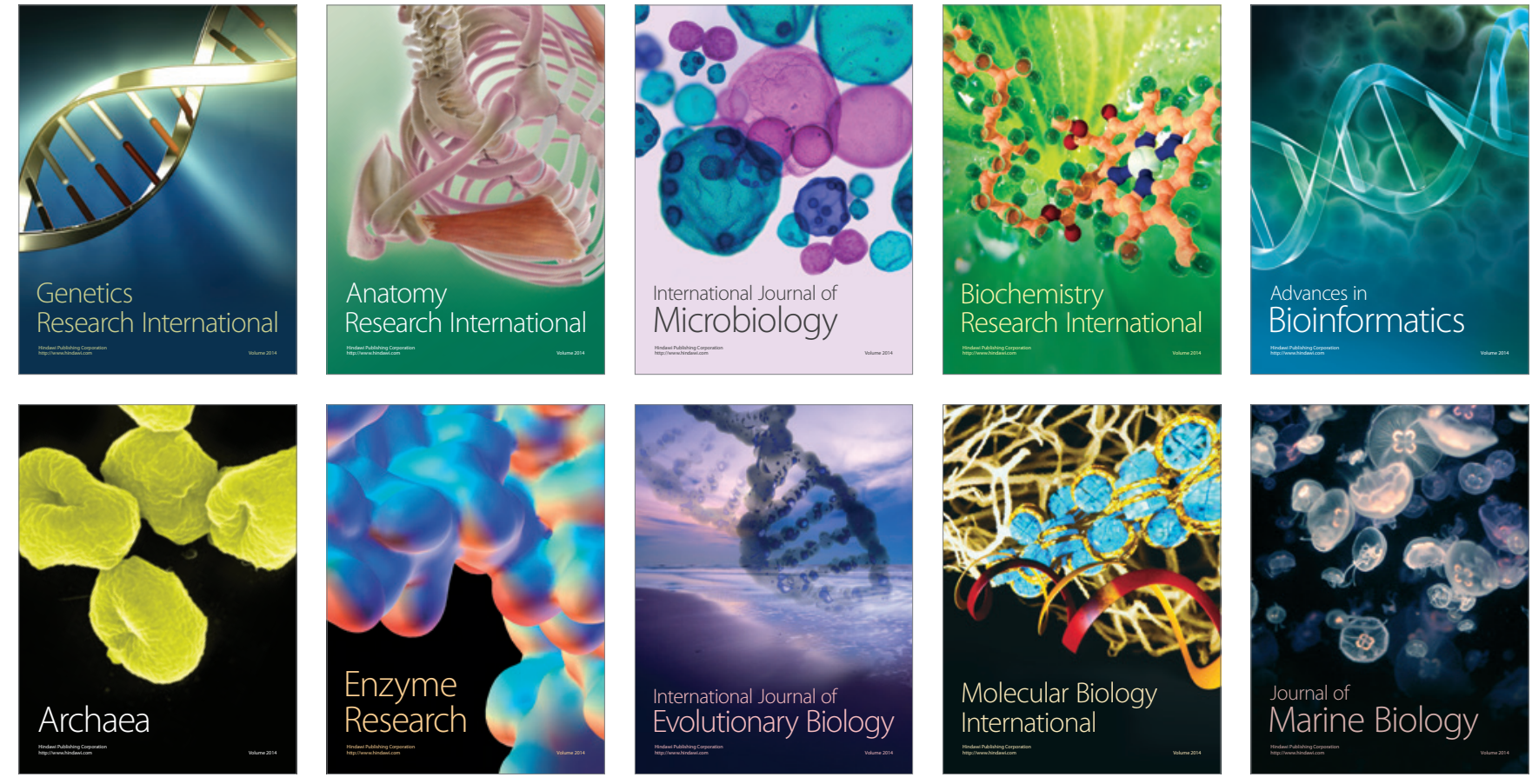